\title{
3D, CHEMICAL AND ELECTROCHEMICAL CHARACTERIZATION OF \\ BLASTED TI6AL4V SURFACES: ITS INFLUENCE ON THE CORROSION BEHAVIOUR
}

\author{
V. Barranco, M.L. Escudero, M.C. García-Alonso* \\ Centro Nacional de Investigaciones Metalúrgicas, CENIM \\ Consejo Superior de Investigaciones Científicas, CSIC
}

Avda. Gregorio del Amo 8, 28040

Madrid, Spain.

\begin{abstract}
The blasting process to increase the roughness of the surface of metallic biomaterials is widely used. As a consequence, one can produce a renewed surface with different topography and chemical composition compared to the original one, which can alter the general corrosion behaviour of the samples. With this idea, the aim of this work is not only the topographical and compositional characterization of blasted surfaces of Ti6Al4V alloy but mainly its influence on the corrosion behaviour of these modified surfaces. The surfaces of Ti6Al4V alloys were blasted with $\mathrm{SiO}_{2} / \mathrm{ZrO}_{2}$ and $\mathrm{Al}_{2} \mathrm{O}_{3}$ particles of different size in order to obtain different roughnesses. To carry out the microstructural and topographical characterization of the blasted surfaces, the scanning electron microscopy (SEM) coupled with an energy dispersive X-ray (EDX), the contact profilometry method and the 3-D characterisation by means of stereo Fe-SEM have been used. By means of stereo Fe-SEM, the roughness and the real surface area of the rough surfaces have been calculated. The microstructural, topographical and

Tel. +34915538900

Fax. +34915347425

e-mail:crisga@cenim.csic.es
\end{abstract}


compositional results have been correlated with the corrosion behaviour of the samples immersed in Hank's solution and studied by means of electrochemical impedance spectroscopy (EIS). The results indicate that the particles and the characteristics of the passive film formed after the blasting process induce to a slight decrease in the capacitance values, but in general, do not alter significantly the general corrosion behaviour of the samples.

Keywords: 3D-Characterisation, stereo-Fe-SEM, Electrochemical impedance spectroscopy (EIS), biomedical surface engineering, Blasted Ti6A14V alloy 


\section{Introduction}

The physical, mechanical and topographical properties of the metallic surface play an important role in the service life of a prosthesis, and determine whether there is an adequate or inadequate response of the different types of cells present in the biological environment. In fact, these properties determine the phenomena occurring at the interface between the implanted device and the biological environment. In vitro studies have reported that smooth surfaces favour human oral fibroblast attachment and soft tissue growth, whereas rough surfaces favour the osteoblasts attachment and the ingrowth of bone $[1,2,3,4]$. The in vivo tests have also confirmed that roughness promotes a better bone fixation to titanium implants $[5,6]$. Osteoblasts have a higher probability to adhere to a rough titanium surface while fibroblasts and epithelial cells adhere mainly to very smooth surfaces $[7,8]$. In the literature, it has been suggested that these findings can be explained by considering that a rough implant enhances both the stress transfer and the mechanical interlocking between bone and implant.

A collection of surface treatment processes are available to alter the surface topography of Titanium and its alloys such as machining, plasma spraying, electrochemical treatments (anodizing), particle blasting or acid etching [9]. Of all of them, perhaps the most widely used process to increase the surface roughness of Titanium and its alloys has been the blasting process [5-10,10,11]. In the blasting process, abrasive particles (alumina, rutile, $\mathrm{SiC}, \mathrm{ZrO}_{2}, \mathrm{SiO}_{2}$, or hydroxyapatite) are forced against the surface by a dragging fluid (usually compressed air but it can also be wet) at a fixed pressure for a certain time. In addition, it is unavoidable that blasting particles induce abrasive pollution [12], which is potentially responsible for modifications in the chemical composition and for the physicochemical properties of blasted surfaces, such as surface 
charge, and/or surface energy of the implant. As a consequence, a renewed surface with different topography and chemical composition compared to the original one is produced and which requires a careful characterization.

There is a very large number of scientific contributions focused on how and how much the surface properties, not independently but simultaneously, can be modified to promote osseointegration and so improve the implant performance [12]. Among these methods, the blasting process is used as an effective method to increase the surface roughness of metallic biomaterials and enhance the in vitro and in vivo behaviour. But it is difficult to assign this improvement to the effect of changes in surface chemistry or/and topographical changes after the blasting process. In some studies, the efforts are being steered towards separating the effects of surface chemistry and topography $[13,14]$ on the response of osteoblasts, in which the roughness is varied but the chemical composition is maintained constant. In other studies $[15,16]$, acid treatments have been applied after the blasting process and thus obtaining a micro roughness on the surface and a reduction of the number of particles remaining on the surface. Nevertheless, it is not clear that the presence of the particles remaining after the blasting process on the surface can produce a deleterious effect on the in vivo implantation. Some authors [17] have stated that the presence of inert alumina particles on titanium implants does not seem to have deleterious effects on osseointegration. In any case, a careful characterization of the surface is needed. Some scientific works have performed quantitative evaluations, after the blasting process on Ti-based surfaces, of how the surface area can be increased and how many grit residues remain on the substrate surface [18]. But, very few studies [19] have been carried out to correlate this quantification with the estimation of the real corrosion behaviour. So, the aim of this 
work is not only the topographical and compositional characterization of blasted Ti6A14V surfaces but mainly its influence on the electrochemical properties and concretely on the corrosion behaviour of these modified surfaces.

\section{Experimental procedure}

\subsection{Sample preparation}

The experiments were carried out on Ti6Al4V (wt\%) alloy supplied by IQL (BIOMET Spain Orthopaedics SL) in the shape of squares of $2.5 \times 2.5 \mathrm{~cm}^{2}$ and $0.5 \mathrm{~cm}$ thickness. Three types of surface conditions were studied. The polished surfaces, hereafter Ti64-P specimens, were prepared by abrading the sample surface on successively finer silicon carbide papers and then mechanically polished with $1 \mu \mathrm{m}$ diamond paste to a mirror like finish surface; and two types of standard rough surfaces, hereafter Ti64-LR (low roughness) and Ti64-HR (high roughness) specimens which were prepared by the implant manufacturer under industrial particle-blasting conditions. In Table 1 the nature and size of the particles are given for each blasted treatment. The samples were washed in running water and ultrasonically cleaned with ethanol before use.

\subsection{Microstructural characterisation}

The microstructural characterization of the surface morphology and the cross sections of selected specimens was carried out by Scanning Electron Microscopy (SEM) with a Field Emission Gun (FEG) coupled with an Energy Dispersive X-ray (EDX) system (Oxford Inca microanalysis system and a windowless detector) for chemical analysis. The samples were examined in a JEOL-6500F microscope at a $15 \mathrm{kV}$ accelerating voltage. 


\subsection{Contact profilometry method}

The surface roughness was determined before and after the surface modification using a profilometer Mitutoyo Surftest 401. A diamond stylus was used, which is reported by the manufacturer to have a tip with a radius of $5 \mu \mathrm{m}$ on a $90^{\circ}$ cone and a contact force of $4 \mathrm{mN}$. Original tracing lengths of $4 \mathrm{~mm}$ were performed and a high pass filter with a cut-off of $0.8 \mathrm{~mm}$ was selected. The roughness parameters were obtained from five line profiles starting from a common origin line and spaced $5 \mathrm{~mm}$ one from each other. The roughness values were evaluated following the norm DIN 4768, in which, $R_{a}$ is the arithmetic average of the absolute values of all points of the profile; $R_{z D I N}$ is the arithmetic average of the maximum peak to valley height of roughness values; $R_{q}$ is the root mean square of the values of all the points of the profile; and $\mathrm{R}_{\max }$ is the maximum

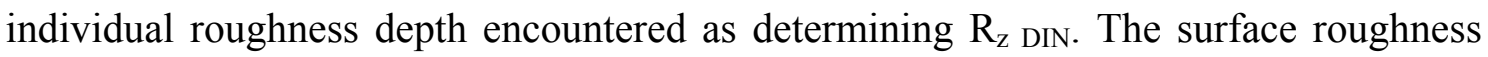
was given as the average surface roughness $\left(\mathrm{R}_{\mathrm{a}}\right)$ in micrometer units at a sensitivity setting of $0.01 \mu \mathrm{m}$.

\subsection{D analysis of stereoscopic SEM-images}

The application of the combination of SEM and stereoscopic techniques was used to characterise the surface topography of the samples. The stereo-SEM is a non-tactile measurement method based on the analysis of stereoscopic images. From the area observed by SEM, two images are captured at different tilt $\mathrm{x}$-angle. This is performed by tilting the specimen holder by the order of 3 to 7 degrees. In this study the tilt angle used was 5 degrees. The resulted two images $\left(0^{\circ}\right.$ and $\left.5^{\circ}\right)$ were imported into the MeX software (Alicona Imaging $\mathrm{GmbH}$ ) and a 3D surface representation was calculated. Starting from stereoscopic SEM images, MeX creates a high density DEM (Digital Evaluation Model) image that forms the basis for subsequent analysis procedures. The 
stereo-SEM method allows the determination of a selected number of profiles, both vertical and horizontally, characterizing the roughness parameters on two axes. The next parameters are obtained: DS - Fractal dimension of selected area; $\mathrm{S}_{\mathrm{a}}$ - Average height of selected area; $\mathrm{S}_{\mathrm{q}}$ - Root-Mean-Square height of selected area; $\mathrm{S}_{\mathrm{p}}$ - Maximum peak height of selected area; $S_{v}$ - Maximum valley depth of selected area; and $\mathrm{S}_{\mathrm{t}}$ - Maximum height of selected area (SP $+\mathrm{SV})$. In addition, a comparative study of the roughness profiles and the determination of the real surface area of the samples with different roughness was done. This fact is quite useful in the study of the features of random surfaces, as these two blasted surfaces studied.

\section{5.- Electrochemical impedance spectroscopy (EIS)}

All the samples were exposed to Hank's solution oxygenated by direct contact with the laboratory atmosphere. The chemical composition of Hank's solution which simulates the physiological human body fluids is given in Table 2. The $\mathrm{pH}$ of the solution was $7.4 \pm 0.1$ over the testing time. The measurements were carried out with the electrolyte at rest (without external stirring). The electrochemical cell was prepared by fixing a glass cylinder onto the metallic sheet and filled with the Hank's solution. The tested area of the sample surface was $0.196 \mathrm{~cm}^{2}$. The electrochemical cell was designed with a saturated calomel electrode (SCE) as the reference electrode, a sheet of platinized titanium as the counter electrode, and the studied samples as the working electrode. Prior to the beginning of the electrochemical measurements, the specimens were maintained for $1 \mathrm{~h}$ in Hank's solution in order to obtain a stable corrosion potential. The electrochemical behaviour was studied by means of electrochemical impedance spectroscopy (EIS). To carry out the impedance measurements, a PAR 273A potentiostat was connected to a 1250 Solartron frequency response analyzer. EIS was 
performed by applying a sinusoidal wave of $10 \mathrm{mV}$ in amplitude at the corrosion potential to the working electrode at a frequency range from $64 \mathrm{kHz}$ to $1 \mathrm{mHz}$ spaced logarithmically (five per decade). The tests were normally repeated twice, checking that they presented reproducibility. When reproducibility was not achieved in a particular condition, a third test was carried out.

\section{Experimental results}

\subsection{Microstructural characterization}

As an example, Figures $1 \mathrm{a}, \mathrm{b}$ and $\mathrm{c}$ show the SEM micrographs of the Ti64-P, Ti64-LR and Ti64-HR samples, respectively (see abbreviation in Table 1). The Ti64-P surface (Figure 1a) shows the duplex microstructure of the Ti6Al4V alloy containing $\alpha$ - and $\beta$ phase. SEM examination of the Ti64-P sample reveals the typical biphasic structure consisting of bright areas ( $\beta$-phase) in a dark matrix ( $\alpha$-phase). With respect to the samples with higher roughness, the surfaces blasted with the lowest sized particles show a more homogeneous surface structure than those blasted with the coarsest particles which produce more irregular surfaces.

The surface examination of the Ti64-LR specimens (Figure 1b) revealed a heterogeneous surface in which particles resulting from the blasting process appear. Figure 2 shows a deeper observation at higher magnification that confirms the presence of these particles. The chemical composition of the surface of the Ti64-LR sample, performed by EDX analysis on different areas (Spectra 1,2 and 3 in Figure 2) is given in Table 3. The spectrum 1 of Table 3 shows that the particle is composed of a mix of silicon and zirconium oxides in almost similar percentages. On the other hand, the atomic percentage of the elements present in an area enriched with these sand particles 
(Table 3-Spectrum 2) indicated that, excluding the oxygen which comes from the different surface oxides, it was mainly formed by $\mathrm{Ti}$, $\mathrm{Si}$ and $\mathrm{Zr}$ in almost similar percentages, $10.18 \%, 9.37 \%$ and $9.22 \%$, respectively. EDX analysis performed on an area "free" of particles, (see in Figure 2, Spectrum 3 and Table 3) revealed that it was mainly composed of Ti and Al with a small percentage of V detected. Surprisingly, a small percentage of Si and Zr was also detected. A deep observation of this area showed that small amounts of particles (less than a $0.5 \mu \mathrm{m}$ mean size) were still remaining on the surface. This fact makes it impossible to evaluate accurately the fraction of the area covered by the $\mathrm{ZrO}_{2} / \mathrm{SiO}_{2}$ particles, since the estimation of the area covered by the smallest particles scattered all over the surface would be subject to considerable error.

The cross sectional observations performed in the Ti64-LR sample, revealed that $\mathrm{SiO} 2 / \mathrm{ZrO} 2$ particles became encrusted on the surface after the blasting process (Figure 3). EDX analysis on the particles confirmed the chemical composition of the these ones. It is interesting to note that the mean thickness of the particle encrusted in the Ti6Al4V surface was in the range of 2 to 3 micrometers.

In the case of the coarsely blasted samples (Ti64-HR), the surface examination of the specimens revealed a more irregular surface in which the $\mathrm{Al}_{2} \mathrm{O}_{3}$ particles of polygonal edges, often broken, resulting from the grit blasting process appeared (Figure 1c). The size of the particles, with an overall size of about $20 \mu \mathrm{m}$, were large enough to make it possible to estimate the fraction of surface area covered by the $\mathrm{Al}_{2} \mathrm{O}_{3}$-grit particles. For this, ten micrographs at 500x magnification of the Ti64-HR were obtained and processed by image analysis (Image $\mathrm{J}$ ). The residual fraction of $\mathrm{Al}_{2} \mathrm{O}_{3}$ particles, which is defined by the ratio of the area covered by the residual encrusted particles to the total 
area of the substrate, was calculated to be about $17 \%$. So, the results showed that the extent of $17 \%$ of the Ti64-HR sample surface is covered with $\mathrm{Al}_{2} \mathrm{O}_{3}$ particles. The percentage obtained is in agreement with the values calculated by other authors for the same size of particles [20,14].

The cross sectional observations performed in the Ti64-HR sample, revealed that the mean thickness of the $\mathrm{Al}_{2} \mathrm{O}_{3}$ particles encrusted in the Ti6Al4V surface was in the range of 3 to 4 micrometers.

\subsection{Surface topography}

\subsubsection{Contact profilometry method}

The $R_{a}, R_{z D I N}, R_{\max }$ and $R_{q}$ mean values and standard deviations obtained from five profile measurements are reported in Table 4. The results of contact profilometry showed significant differences between the roughness parameters obtained for all the samples. As expected, the Ti6A14V surface coarsely blasted with the $\mathrm{Al}_{2} \mathrm{O}_{3}$ particles $(500 \mu \mathrm{m}$ in size) showed the highest roughness amplitude parameters. The average roughness $\left(R_{a}\right)$ exhibited an increase of $71 \%$ compared to the $R_{a}$ parameter obtained for the finely blasted Ti64-LR samples. In the case of the $Y_{1}$ to $Y_{5}$ of five consecutive sampling sections over the filtered profile $\left(R_{z}\right.$ DIN $)$, the mean value obtained for the coarsely blasted Ti64-HR sample shows an increase of $67.5 \%$ compared to the values obtained for the fine blasted Ti64-LR surface. The parameters $\mathrm{R}_{\mathrm{q}}$ and $\mathrm{R}_{\max }$ are increased by 70 and 69 percent, respectively, in the case of the Ti64-HR compared to the Ti64-LR sample. These results give an overall idea of the differences in the topographic features of the studied surfaces. 


\subsubsection{D analysis of stereoscopic SEM-images}

Figures $4 \mathrm{a}$ and $\mathrm{b}$ show the 3D-Fe-SEM surface topography micrographs obtained on the surfaces of the Ti64-LR and Ti64-HR samples, respectively. The 3D micrographs have been reconstructed by MeX from the stereo par formed by the micrographies obtained at 0 and +5 degrees from the Ti64-LR and Ti64-HR surfaces. The roughness analysis of the selected regions has been done using the same analysis conditions and following the same criteria for all the samples.

Figure 5a shows the surface topography of a representative region of the Ti64-HR surface. This micrograph shows the characteristic features of this surface, as a residual $\mathrm{Al}_{2} \mathrm{O}_{3}$ particle (in the top-left-hand corner) and a region with high peaks (in the topright-hand corner). The selected region with the grid is characterized by an area mainly formed by cavities and deep valleys. Around this selected region, the surface topography shows more attenuated rough features. All of this makes the roughness analysis more complicated than in the case of a non-random surface. The roughness amplitude parameters obtained in the selected region (Figure 5a), from 20 horizontal and 20 vertical traces of $40 \mu \mathrm{m}$ and $25 \mu \mathrm{m}$ length respectively, and a high pass filter with a cut-off of $0.25 \mu \mathrm{m}$, are shown in Table 5 . In this case, the parameter $R_{a}$ is the mean average roughness of profiles ( $x$ and $y$-axis), $R_{z}$ is the mean maximum height of roughness profiles, $R_{p}$ is the mean maximum peak height of roughness profiles and $R_{q}$ is the mean root-mean-square roughness of profiles. Additional and complete information about the selected area is given by the statistical area parameters summarized in Table 6. 
Besides the topographical characterization, the determination of the real surface area has been obtained by MeX, for each blasted surface. Table 7 shows the results obtained. So, knowing the ratio between the true are and the projected area (geometrical area), it is possible to obtain the values of the real surface in contact with the electrolyte. The increase in the real area due to the increase in roughness is clearly shown. The polished sample (Ti64-P), taken as a reference, has a projected area of $0.196 \mathrm{~cm}^{2}$ equal to the true area. Thus, the true area / projected area ratio is 1 . This projected area is the same for the three samples. The Ti64-LR sample, has a true area of $0.2195 \mathrm{~cm}^{2}$ and the Ti64HR sample has a true area in contact with the electrolyte of $0.3014 \mathrm{~cm}^{2}$, that is approximately double. This calculation made it possible to estimate the real area of the samples used in corrosion experiments, i.e. the real area in contact with the electrolyte.

With respect to the particles encrusted in the surface, in Figure $5 \mathrm{~b}$ it can be seen that the particles are not only broken but are also flattened. To find out the softness of the particle surface, 20 vertical and horizontal roughness profiles were measured on the surface of the $\mathrm{Al}_{2} \mathrm{O}_{3}$ particle. The roughness amplitude parameters are shown in Table 5. Furthermore, from the selected region of the particle surface a projected area of 48.95 $\mu \mathrm{m}^{2}$ and a true area of $51.77 \mu \mathrm{m}^{2}$ could be obtained which gives as a result, a true area/projected area ratio of 1.05 and a fractal dimension of 2.002 .

\subsection{Electrochemical impedance spectroscopy (EIS)}

The Bode impedance diagrams of the Ti64-P, Ti64LR and Ti64-HR samples immersed in Hank's solution after $60 \mathrm{~min}$ appear in Figure 6. It can be seen that there are differences of about $1 \mathrm{M} \Omega$ between the impedance values at the lowest frequencies of the samples. The impedance modulus values at the lowest frequency $\left(10^{-3} \mathrm{~Hz}\right)$ is 
around $510^{6}$ ohms, varying from $410^{6}$ to $6.210^{6}$ for the highest and the lowest roughness samples, respectively.

Figure 7 shows the impedance diagrams obtained taking into account the values of the real area (Table 7) exposed to the electrolyte. The corrected value of real area produces a decrease of about one order of magnitude in the impedance modulus values.

The impedance diagrams obtained for all the samples have been fitted considering the equivalent electrochemical circuit models of Figure 8. The criteria used in estimating the quality of the fit were evaluated firstly with the chi-square value, $\chi^{2} \leq 1 \times 10^{-3}$, and secondly with the lower estimative errors (in \%) for all the components. The best fit of the experimental impedance data was obtained by using the equivalent circuit proposed in Figure 8a. The next elements have been chosen in the circuit: CPE, Constant phase element, simulating a non-ideal behaviour of the capacitor due to the passive oxide film and to the particles and $\mathrm{R}$, is the resistance of the surface (passive oxide film and particles). Table $8 \mathrm{a}$ shows the results obtained by fitting using the equivalent circuit displayed in Figure 8a.

For a precise evaluation of these parameters, table 8-b was drawn up relating the values of the fit to the real area obtained by stereo-SEM method (table 7). The capacitance values obtained are in the same range from 1.42 to $6.12 \times 10^{-5}\left(\mathrm{~S} / \mathrm{s}^{\mathrm{n}}\right) / \mathrm{cm}^{2}$ for all the samples. For comparison purposes, the capacitance values have been converted into $\mathrm{F} / \mathrm{cm}^{2}$, considering the $\mathrm{n}$ exponent in each case. A capacitance value of $1.51 \times 10^{-5} \pm 10^{-7} \mathrm{~F} / \mathrm{cm}^{2}$ is obtained for the Ti64-P sample, $4.25 \times 10^{-6} \pm 10^{-7} \mathrm{~F} / \mathrm{cm}^{2}$ for the Ti64-LR and $3.52 \times 10^{-6}$ $\pm 10^{-7} \mathrm{~F} / \mathrm{cm}^{2}$ in the case of the Ti64-HR sample. 


\section{Discussion}

A suitable surface roughness on the metallic biomaterial will facilitate different biological/implant interfacial phenomena, as for example, smooth surfaces favouring human oral fibroblast attachment or rough surfaces that favour osteoblast attachment and the ingrowths of bone [21,22,23,24]. The blasting process is a very common method to increase the surface roughness of the biomaterials. The size and nature of the particles and the operating conditions are variables that determine the final topography and the composition of the surface of the biomaterial. So, the correct characterization of these new surfaces is needed to understand how these modifications influence the corrosion behaviour.

In this work the estimation of the roughness parameters by the combination of contact profilometry and stereo-SEM method has provided a wide-ranging characterization of the samples. Each method has its own limitations in terms of resolution and scan range and therefore it is not possible to measure topographic features across a wide range of dimensions by using only one method [26].

The roughness values shown in Table 4 obtained by means of contact profilometry, provided an overall idea of the differences in the topographic features of the studied surfaces. The Ti64-HR surface, coarsely blasted with the $\mathrm{Al}_{2} \mathrm{O}_{3}$ particles, had the highest roughness amplitude parameters with an average roughness $\left(R_{a}\right)$ of $4.7 \mu \mathrm{m}$, with an increase of $71 \%$ compared to the $\mathrm{R}_{\mathrm{a}}$ parameter obtained for the fine blasted Ti6Al4V surface (Ti64-LR). The determination of the optimal roughness of adhesion of osteoblasts is not easy, but some researchers have established that the optimal average 
roughness is between 3 and $5 \mu \mathrm{m}$ [25], in which range the Ti64-HR sample is included. However, although the average roughness is the most widely used parameter to describe the overall roughness of the samples, some authors have admitted that there exist other roughness parameters such as the distance between peaks and the peak-valley distance, that in the case of the characterization of implant surfaces, define better the type of surface on which the osteoblasts prefers to adhere [26]. These range of values should not exceed the ability of the cell to form attachments on two or more peaks (no more than $20 \mu \mathrm{m}$, approximately), otherwise the cell would sense a rough surface as smooth.

A limitation of the contact profilometry method is the insufficient lateral resolution to characterize small topographic features in the range $\leq 0.1 \mu \mathrm{m}$, often found on roughened blasted samples, means that an area with microcavities, such as those shown in Figure 5a, can not be resolved by contact profilometry. On the other hand, the particles encrusted in the surface, to a greater or a lesser degree, reach several micrometers in length in some cases. This causes small jumps on the tip when the surface is scanned. As result of the above mentioned about contact profilometry, the roughness parameters can be overestimated, in this kind of blasted surfaces. One can say that on the surface, created by the blasting process, the cells may form different focal attachments that results in a phenotype that is distinct from that seen on the grooved surface with the same degree of roughness [22]. This is the reason why the common practice of applying "integral" roughness parameters can be an incomplete and unsatisfactory way of describing this kind of surface topographies. Instead of that, wavelength-dependent roughness evaluation is shown to be a suitable method for the description of surface topographies in various characteristic roughness ranges, as well as being a useful indicator of the effect of surface treatment processes [24]. This roughness evaluation 
has been used on the blasted Ti6Al4V samples through the stereo-SEM method whose characterization has been described in the experimental part of this paper.

The stereo-SEM method allows the visual observation of the measured surface and this has made possible the individual characterization of particles and micro-areas with different roughnesses (see Figures $5 \mathrm{a}$ and $\mathrm{b}$ ). The method possesses a high lateral resolution, that enables us to characterize the topographical features in the sub-micron scale. The detailed characterization by the stereo-SEM method verified that there are areas with a mean $R_{a}$ value of $0.6465 \pm 5 \times 10^{-4} \mu$ m (Table 5). These roughness values obviously differ from those obtained by contact profilometry. Such differences occur because the contact profilometry and stereo-SEM method, besides differing in the physical principles underlying their use, also differ in the length of the surfaces scanned. These facts are known to affect the values of integral roughness parameters such a $R_{a}$, $\mathrm{R}_{\mathrm{z}}, \mathrm{R}_{\max }$ and $\mathrm{R}_{\mathrm{q}}$ [24]. The statistical area parameters obtained by the stereo-SEM analysis complete the topographical information. For the area selected on the Ti64-HR sample in Figure 5a, an average height of selected area (Sa) of $1.4422 \pm 5 \times 10^{-4} \mu \mathrm{m}$ was found (Table 6). The sum of maximum peak height $(\mathrm{Sp})$ and the maximum valley depth (Sv) gave a maximum height of $10.9405 \pm 5 \times 10^{-4} \mu \mathrm{m}$ in the selected area, which is in the range of those $\left(\mathrm{R}_{\mathrm{a}}\right.$ and $\mathrm{R}_{\mathrm{q}}$ ) obtained by contact profilometry. In addition, by using this method it has been possible to estimate a real area in contact with the electrolyte, which is an especially important parameter in order to evaluate the corrosion behaviour of the metallic surfaces. The difference between the initially estimated area (projected) and the real area calculated by this method is about 1.5 times higher than the projected area previously considered (Table 7). The increase of the area in contact with the medium of the blasted Ti6Al4V samples affects both the capacitance and the resistance values, i.e., 
properties of the surface which are very important parameters in the electrochemical characterization of the samples.

Another interesting result obtained from the characterization made by SEM and EDX, is the percentage of surface area covered by contamination of the blasted particles. In the case of the Ti64-LR sample, the covered area fraction was difficult to estimate because of the impossibility of making reliable measurements. In this case, the $\mathrm{SiO}_{2} / \mathrm{ZrO}_{2}$ particles were scattered on the surface and their contribution was difficult to separate from the free area of the Ti64-LR sample. However, in the case of the Ti64-HR, the size of the particles encrusted in the sample was high enough to allow the estimation of a covered area of $17 \%$ without making a significant error.

Up to this point, the blasted surfaces have been characterized, both topographically and chemically, by contact profilometry, SEM, EDX and stereo-SEM images. Now, the physicochemical changes of these modified surfaces immersed in the Hank's solution will be discussed through of its corrosion behaviour.

The blasting particles used in this study have been $\mathrm{Al}_{2} \mathrm{O}_{3}, \mathrm{SiO}_{2}$ and $\mathrm{ZrO}_{2}$. These oxides have a dielectric constant of $\varepsilon_{\mathrm{r}}\left(\mathrm{Al}_{2} \mathrm{O}_{3}\right)=9.5, \varepsilon_{\mathrm{r}}\left(\mathrm{SiO}_{2}\right)=3.9$ and $\varepsilon_{\mathrm{r}}\left(\mathrm{ZrO}_{2}\right)=10-18$. These particles can be considered as insulating zones in the surface, since the particles are compact, no porous and do not react with the electrolyte, so they do not take part in the corrosion reactions but their contribution in the capacitance values measured could be important. 
On the other hand, the spontaneous passive oxide layer which is formed on the Ti6Al4V, is in the range of 5 to $8 \mathrm{~nm}$ thick and is mainly composed of titanium oxides and hydroxides and a small percentage of $\mathrm{Al}_{2} \mathrm{O}_{3}+\mathrm{AlO}(\mathrm{OH})$. The titanium oxide that forms the passive film in the highest atomic percentage is $\mathrm{TiO}_{2}$. At room temperature, $\mathrm{TiO}_{2}$ is in its crystalline form named anatase, and has a dielectric constant of $\varepsilon_{\mathrm{r}}\left(\mathrm{TiO}_{2}\right.$ $($ Anatase $)=48$. A parallel study carried out by XPS by our research group, about the chemical characterization of the passive layer of Ti6Al4V alloy, has shown that $93.4 \%$ of the film is mainly $\mathrm{TiO}_{2}$ and $6.6 \%$ is $\mathrm{Al}_{2} \mathrm{O}_{3}$. By using the corresponding dielectric constants of $\mathrm{TiO}_{2}$ and $\mathrm{Al}_{2} \mathrm{O}_{3}, 48$ and 9.5, respectively, it has been estimated that the resultant dielectric constant of the passive layer is $\varepsilon_{\mathrm{r} \text { Ti64-P }}=45.46$. The differences between the dielectric constants of the oxides which are present in the outer blasted surfaces will cause different electrochemical behaviour that can be observed through the capacitance values.

The theoretical capacitance values of Ti6Al4V surfaces will be calculated by using the known formula of a flat capacitor, for the lowest and highest roughened samples (Ti64$\mathrm{P}$ and Ti64-HR). In the case of the Ti64-P samples, the real and projected area is the same. The thickness of this passive film is in the range of 4 to $8 \mathrm{~nm}$. Being the tested area of $0.196 \mathrm{~cm}^{2}$ and $\varepsilon_{\mathrm{r}}(\mathrm{Ti} 64-\mathrm{P})=45.46$, the theoretical capacitance values vary between 1.98 and $0.99 \mu \mathrm{F} / \mathrm{cm}^{2}$.

For the Ti64-HR samples, about $17 \%$ of the surface area is covered by the particles. Thus, for a real area of $0.2681 \mathrm{~cm}^{2}$ free of particles, theoretical capacitance values of the passive oxide film, between 2.7 and $1.4 \mu \mathrm{F} / \mathrm{cm}^{2}$ have been estimated. On the other hand, considering that the encrusted $\mathrm{Al}_{2} \mathrm{O}_{3}$ particles have a thickness between 1 and $3 \mu \mathrm{m}$, a 
covered area of $0.051 \mathrm{~cm}^{2}$ and $\varepsilon_{\mathrm{r}}\left(\mathrm{Al}_{2} \mathrm{O}_{3}\right)=9.5$, the theoretical capacitance values obtained vary between 1.5 and $4 \times 10^{-10} \mathrm{~F} / \mathrm{cm}^{2}$.

Between the theoretical capacitance of the passive film and the alumina particles there are four orders of magnitude. The total capacitance equivalent of the Ti64-HR surface is $2.000275 \times 10^{-6} \mathrm{~F} / \mathrm{cm}^{2}$. This value indicates that the influence of the particles on the overall capacitance is negligible. It should be pointed out that this theoretical value is in agreement with the experimental capacitance data obtained from electrochemical impedance spectra. This means that the effect of the passive oxide film capacitance prevails over the particle capacitance.

With respect to the value of the resistance, if the encrusted particles can be considered as insulators, the measured values of resistance would be related to the real area of passive oxide film free of particles. In the case of the Bode diagram of the impedance modulus versus frequency shown in Figs. 7 and 8, it was observed the difference in the slope, in the frequency range from $1 \mathrm{mHz}$ to $10 \mathrm{~Hz}$, of $-1,-0.902$ and -0.89 from the lowest roughness (Ti64-P) to the highest roughness (Ti64-HR) samples. These values indicate that the electrochemical mechanisms that take place on the solution/metallic surface interface in Ti64-P samples are mainly governed by the activation process (the case of slope -1 ) but other processes such as diffusion and/or mass transfer in the heterogeneous surface make a slight contribution in the corrosion mechanisms of the blasted samples, that is greater as the roughness increases.

The equivalent circuit to explain the experimental impedance results for the blasted Ti6Al4V samples proposed in the Figure 8a seems to be the most suitable. In this case, 
the CPE is mainly related to the overall capacitance contribution due to the passive oxide film formed spontaneously on the Ti6Al4V alloy surface. From the capacitance values obtained from the fitting in the Table $8 \mathrm{a}$, for the different studied samples, it is proved a decrease in the capacitance values is produced comparing both the polished surfaces and blasted surfaces. The correction of the capacitance values, in order to normalise them, considering the real area instead of the projected area (Table $8 b$ ), reduces about five times the capacitance values for the blasted surfaces. Taking into account that the error in the measurement is $\pm 10^{-7}$ for all values, then these slight differences must be considered. So, the decrease in capacitance values can be assigned to both the presence of the particles and the nature of the passive oxide film formed after the blasted process.

Likewise, the resistance represents the overall resistance due to the particles and the passive film contribution. But, as has been previously mentioned, the particles are acting as a barrier to the electrolytic conduction, thus the resistance in the circuit is mainly the resistance due to the passive oxide film free of particles.

Each blasting process produces different degrees of deformation in the blasted surface. It is known that the mechanical and physical properties (hardness, fracture toughness and density) of the particles impacted determine the final state of the surface. The energy transferred to the substrate depends on its mass and its facility for breaking. The higher the energy transferred is, the higher the cold-working surface layer with higher residual stresses. This may alter the nature of the passive oxide film formed and consequently can also influence the corrosion behaviour. So, the resistance of the passive Ti6Al4V film submerged in the Hank's solution, will depend on the porosity 
and the nature of the passive film generated after the blasting process. The thinner and more porous the passive layer is, the lower the passive film resistance.

In conclusion, the blasting process alters topographical and chemically the surface of the samples. These modifications induce to a decrease in the capacitance values of the surfaces. In addition, different reaction mechanisms involved in the corrosion process begin to be important, such as the mass transport and/or diffusion mechanisms. However, the high reactivity of $\mathrm{Ti}$ and $\mathrm{Al}$ with the oxygen ensures the formation of the passive film that protects the implant material, as it has been widely proved in this and other studies $[27,28,29,30]$. This is in agreement with the excellent in vivo results obtained with Ti64 samples blasted with alumina, in which osseointegration is not affected by either the presence of alumina particles or the increase of roughness [17]. The latter can be consider as a possible generator of weak points in the passive oxide film that can give rise to the ion release. The susceptibility to pitting corrosion of blasted samples can be affected by the accumulation of stress in punctual zones of the deformed surface and to cause the easier breakdown of the passive film with the subsequent metallic ion release in very aggressive media. A comparative study of susceptibility to pitting corrosion of different blasted surfaces will be published separately.

\section{Conclusions}

- It has been proved that the contact profilometry method is not enough in itself to describe the real topography of the surface by blasting process. 
- Stereo-SEM method allows the visual observation of the measured surface and this has made possible the individual characterization of particles and micro-areas with different roughnesses. The method possesses a high lateral resolution, that allows us to characterize the topographical features in the sub-micron scale. Also, by this method the estimation of the real area in contact with the electrolyte has been possible.

- The detailed characterization of the surface, in terms of the real area and the covered fraction of particles, has allowed us to study in detail the electrochemical properties of the surface.

- The particles and the nature of the passive oxide film formed after the blasted process, have induced to a decrease in the capacitance values measured in Hank's solution.

\section{References}

[1] D.L. Cochran, J. Simpson, H.P. Weber, D. Buser, J. Oral Maxillofac. Implants 9 (1994) 289.

[2] K.T. Bowers, J.C. Séller, B.A. Randolph, D.G. Wick, C.M. Michaelis, Int. J. Oral Maxillofac. Implants 7 (1992) 302.

[3] K. Mustafa, B.S. López, K. Hultenby, A. Wennerberg, K. Arvidson, Clin. Oral Impl. Res., 9 (1998) 195.

[4] M. Wieland, M. Textor, B. Chehroudi, D. M. Brunette, Biomaterials 26 (2005) 1119.

[5] A. Wennerberg, T. Albrektsson, C. Johansson, B. Andersson, Biomaterials 17 (1996) 15.

[6] A. Wennerberg, T. Albrektsson, J. Lausmaa, J. Biomed. Mater. Res. 30 (1996) 251. 
[7] C. Larsson, P. Thomsen, B.-O. Oronsson, M. Rodahl, J. Lausmaa, B. Kasemo, L.E. Ericson, Biomaterials 17 (1996) 605.

[8] K. Gotfredsen, L. Nimb, E. Hjörting-Hansen, J.S. Jensen, A. Holmén, Clin. Oral Impl. Res. 3 (1992) 77.

[9] A. Bagno, C. Di Bello, J. Mater Sci: Mater. Medicine 15 (2004) 935.

[10] K. Mustafa, A. Wennerberg, J. Wroblewski, K. Hultenby, B.S. López, K. Arvidson. Clin. Oral Impl. Res. 12 (2001) 515.

[11] H.J. Ronold, S.P. Lyngstadaas, J.E. Ellingsen, Biomaterials 24 (2003) 4559.

[12] M.G. Diniz, G.A. Soares, M.J. Coelho, M.H. Fernandes, J. Mater. Sci:- Mater. M. $13(2002) 421$.

[13] M. Wieland, B. Chehroudi, M. Textor, D.M. Brunette, J. Biomed. Mater. Res. 60 (2002) 434.

[14] A. Gaggl, G. Schultes, W.D. Müller, H. Kärcher, Biomaterials 21 (2000) 1067.

[15] E. Conforto, B.-O. Aronsson, A. Salito, C. Crestou, D. Caillars, Mater. Sci. Eng. C $24(2004) 611$.

[16] D. Perrin, S. Szmukler-Moncler, C. Echikou, P. Pointaire, J.P. Bernard, Clin. Oral Impl. Res. 13 (2002) 465.

[17] A. Piatelli, M. Degidi, M. Paolantonio, C. Mangano, A. Scarano, Biomaterials 24 (2003) 4081.

[18] S. Amada, T. Hirose, T. Senda, Surface and Coatings Tech. 111 (1999) 1.

[19] M. Simon, C. Lagneau, J. Moreno, M. Lissac, F. Dalard, B. Grosgogeat, Eur. J. Oral Sci. 113 (2005) 537.

[20] C. Aparicio, F.J. Gil, C. Fonseca, M. Barbosa, J.A. Planell, Biomaterials 24 (2003) 263. 
[21] D.L. Cochran, J. Simpson, H.P. Weber, D. Buser, International J. Oral Maxillofac. Implants 9 (1994) 289.

[22] K.T. Bowers, J.C. Séller, B.A. Randolph, D.G. Wick, C.M. Michaelis, Int. J. Oral Maxillofac. Implants 7 (1992) 302.

[23] K. Mustafa, B.S. López, K. Hultenby, A. Wennerberg, K. Arvidson, Clin. Oral Impl. Res., 9 (1998) 195.

[24] M.Wieland, P.Hänggi, W.Hotz, M.Textor, B.A.Keller, N.D.Spencer, Wear 237 (2000) 231.

[25] J.Y. Martín, Z. Schwartz, T.W. Hummert, D.M. Schraub, J. Simpson, J. Lankford, D.D. Dean, D.L. Cochran, B.D. Boyan, J. Biomed. Mater. Res. 29 (1995) 389.

[26] A. Abron, M. Hopfensperger, J. Thompson, L.F. Cooper, J. Prosthet. Dent. 85 (2001) 40 .

[27] N.D. Tomashov, G.P. Chernova, Y.S. Ruscol, G.A. Ayuyan, Electrochimica Acta $19(1974) 159$.

[28] J. Pan, D. Thierry, C. Leygraf, Electrochimica Acta 41 (1996) 953.

[29] A.W.E. Hodgson, Y. Mueller, D. Forster, S. Virtanen, Electrochimica Acta 47 (2002) 1913.

[30] S. Luiz de Assis, S. Wolynec, I. Costa, Electrochimica Acta 51 (2006) 1815. 